\title{
APLIKASI VIDEO KLIP DENGAN RUBRIK PENILAIAN TERHADAP PENINGKATAN KETERAMPILAN PROSES PADA PEMBELAJARAN MICRO TEACHING MAHASISWA PROGRAM STUDI BIOLOGI
}

\author{
Abdul Rauf \\ Program Studi Pendidikan Biologi, FKIP, Universitas Tadulako \\ rauvunta@gmail.com
}

\begin{abstract}
ABSTRAK
Jenis penelitian ini adalah penelitian eksperimen dengan aplikasi video klip dengan rubruk penilaian pada matakuliah micro teaching sebagai upaya pemberian pengalaman kepada mahasiswa peserta agar mampu menguasai keterampilan mengajar untuk memasuki reel teaching pada pelaksanaan program pengalaman lapangan (PPL) di berbagai sekolah. Metode latihan yang digunakan adalah melaksanakan proses pembelajaran secara mikro melalui pengambilan gambar secara langsung pada masing-masing individu dan selanjutnya dievaluasi keterampilan dan actingnya melalui rubric keterampilan proses. Hasil evaluasi pelaksanaan tersebut diberikan nilai dalam bentuk persen. Jika peserta belum mencapai standar penilaian minimal 85\%, wajib mengulang kembali sampai mencapai standar tersebut. Capaian nilai yang diperoleh melalui penerapan video klip dan rubric penilaian keterampilan proses akan dibandingkan dengan mahasiswa lain yang pembelajaran mikro tidak menggunakan kedua hal tersebut. Perbandingan hasil pengamatan terhadap penguasaan keterampilan proses dari kedua kelompok mahasiswa tersebut menjadi dasar perhitungan dalam penarikan kesimpulan.
\end{abstract}

Kata Kunci: Aplikasi, Video klip, Rubrik Penilaian, Keterampilan Proses

\begin{abstract}
This type of research is an experimental study with the application of video clips with assessment articles on micro teaching courses as an effort to provide experience to student participants to be able to master teaching skills to enter teaching reel in the implementation of field experience programs (PPL) in various schools. The training method used is to carry out the micro-learning process through taking pictures directly to each individual and then evaluating skills and acting through rubric process skills. The results of the evaluation of the implementation are given in percent. If the participant has not reached a minimum assessment standard of $85 \%$, it must be repeated until it reaches that standard. Achievement of values obtained through the application of video clips and rubric assessment of process skills will be compared with other students who micro-learning does not use both of these things. Comparison of observations on the mastery of process skills from the two student groups is the basis of calculations in drawing conclusions.
\end{abstract}

Keywords : Applications, Video clips, Assessment Rubrics, Process Skills

\section{PENDAHULUAN}

meningkatkan kualitas sumber daya manusia Indonesia, agar menjadi manusia Indonesia yang beriman, mandiri, maju, cerdas, kreatif, terampil, bertanggungjawab serta produktif (Depdiknas, 2007). Peran penting ini harus mendapat tempat yang khusus dalam pengelolaan pendidikan. Oleh karena itu berbagai upaya telah dilakukan untuk meningkatkan kualitas sumber daya manusia tersebut termasuk calon guru yang diproduksi oleh setiap lembaga pendidikan.

Mahasiswa harus memiliki keterampilan yang optimal dalam rangka 
menghadapi tugas-tugas keguruan pada berbagai jenjang pendidikan. Tugas tersebut adalah mengajar, tugas ini merupakan tugas pokok yang memberikan arahan pada proses pembelajaran untuk mencapai tujuan pendidikan yang diinginkan. Pada pelaksanaan tugas tersebut calon guru harus lebih banyak memiliki pengetahuan dan keterampilan yang memadai agar tugas tersebut dapat lebih efektif dilakukan. Tugas lembaga pendidikan dalam hal ini adalah menyiapkan semaksimal mungkin pengalaman-pengalaman pembelajaran tersebut kepada calon guru (mahasiswa). Untuk kebutuhan tersebut setiap program studi yang ada pada Fakultas Keguruan dan Ilmu Pendidikan Universitas Tadulako mencantumkan matakuliah microteaching sebagai sarana pembentukan keterampilanketerampilan mengajar pada calon guru (mahasiswa). Salah satu diantara program studi tersebut adalah program studi pendidikan biologi.

Hasil observasi terhadap kinerja yang dilakukan oleh mahasiswa yang mengadakan praktek pengalaman lapangan (PPL) di sekolah-sekolah menunjukkan bahwa keterampilan mengajar peserta PPL tersebut umumnya rendah, terutama dari segi kemampuan dalam memberikan pemaknaan terhadap materi dan proses pembelajaran, minimal untuk membuat siswa dapat termotivasi dalam melakukan proses pembelajaran. Calon guru umumnya menjalankan pembelajaran dengan cara menjelaskan materi kepada anak (siswa) dengan cara yang sama, tidak variatif, kaku tidak pleksibel dan kurang memberikan kesempatan untuk melakukan proses belajar atau melakuan dengar pendapat dengan siswa, akibatnya siswa kurang mendapat kesempatan untuk melakukan sendiri atau bersama kelompoknya dalam proses pembelajaran, bahkan sering bertindak lain yang tidak sesuai dengan harapan sebagaimana dalam teori pembelajaran yaitu perubahan tingkah laku yang positif.

Paradigma mengajar seperti itu, tentu saja tidak sepenuhnya salah, tetapi perlu ditinjau kembali, lalu diperbaiki untuk mendapatkan luaran yang sesuai. Untuk kebutuhan tersebut diperlukan upaya-upaya secara kontinu dengan memberikan teori dan latihan keterampilan dikalangan calon mahasiswa, agar pembelajaran lebih terfokus kepada siswa (student learning cetered). Salah satu upaya yang dipandang perlu untuk memberikan pengalaman-pengalaman pembelajaran tersebut kepada mahasiswa (calon guru) adalah dengan memanfaatkan beberapa pendekatan dalam pembelajaran mikro secara terus menerus, konsisten, dan disesuaikan dengan kemajuan penguasaan ketarampilan pada calon guru, terutama kemajuan penguasaan teori, keterampilan membuat perangkat pembelajaran dan keterapilan mengajar.

Sanjaya, (2008) mengemukakan bahwa banyak faktor yang mempengaruhi upaya tersebut antara lain: kondisi mahasiswa yang berbeda, pemahaman guru atau dosen atas perangkat pembelajaran yang diaplikasikan, fasilitas dan sistem pengajaran yang digunakan dan pemantauan proses pembelajaran. Pemahaman faktorfaktor tersebut pada mahasiswa calon guru memerlukan analisis secara saksama agar tujuan pembelajaran mikro dapat secara maksimum dikuasai oleh peserta matakuliah mikro teaching sebagai upaya pengayaan pengalaman mengajar untuk menghadapi reel teaching dalam program praktek pengalaman lapangan (PPL).

Berdasarkan hal tersebut di atas, maka diperlukan koreksi-koreksi menyeluruh terhadap berbagai komponen keterampilan mengajar calon guru (mahasiswa) yang wajib ada sebagai syarat untuk melakukan reel teaching di sekolah. Salah satunya melatih mahasiswa dalam menguasai keterampilan mengajar dengan menggunakan video klip yang dikontrol melalui lembar observasi penguasaan keterampilan dengan berbagai item indikatornya. Penggunaan Video Klip dengan rubrik penilaian keterampilan tersebut dapat memberikan arah dan pengarahan proses latihan pelaksanaan pembelajaran baik oleh dosen maupun mahasiswa, sehingga perkembangan penguasaan keterampilan dapat dipantau dan dievaluasi secara efektif dan efisien.

Video klip dikenal dengan sebuah tayangan audio dan visual yang durasinya berkisar antara 15-30 menit atau lebih yang memvisualisasikan gaya dan suara dari mahasiswa dalam melaksanakan proses 
pembelajaran. Video klip yang dibuat oleh mahasiswa merupakan alat yang dapat membantu mereka dalam menyampaikan pesan pembelajaran yang mereka inginkan secara terstruktur, bebas kepada audians atau pengamat. Dengan kata lain, video klip mampu menunjukkan atau mengkomunikasikan tampilan atau acting dari setiap mahasiswa peserta micro teaching sebagai sarana latihan untuk meningkatkan keterampilan mengajarnya sesuai dengan criteria dalam indicator rubric penilaian keterampilan mengajar. Dengan demikian antara video klip yang dibuat oleh mahasiswa dengan rubric penilaian yang digunakan oleh untuk menilai pengusaan keterampilan mengajar tersebut memiliki hubungan satu dengan lainnya.

Melalui penerapan video klip dan rubric penilaian keterampilan mengajar tersebut diharapkan dapat membantu dosen dan mahasiswa untuk melatih keterampilan mengajar mahasiswa calon guru secara berulang-ulang dalam kurun waktu satu semester. Capaian penguasaan keterampilan mengajar oleh mahasiswa dianggap tuntas setelah mencapai $85 \%$ total item indicator yang dinilai. Mahasiswa peserta yang belum mencapai angkah tersebut wajib mengulang dan mengetahui item indicator keterampilan mengajar yang masih perlu diperbaiki untuk mencapai ketuntasan sebagaimana telah disebutkan di atas. Proses pembuatan dan penayangan video klip beserta rubric penilaiannya perlu dikaji lebih jauh melalui sebuah penelitian untuk memperoleh hasil yang valid dan reliable sehingga perangkat tersebut diharapkan dapat dimanfaatkan dengan hasil yang lebih baik.

\section{METODE PENELITIAN}

Jenis penelitian ini adalah penelitian eksperimen dengan mengaplikasikan video klip dan rubric penilaian pada pembelajaran mikro (micro teaching) untuk meningkatkan keterampilan proses pada mahasiswa program studi pendidikan biologi.

Rancangan penelitian menggunakan rancangan percobaan satu factor dimana video klip dengan rubric penilaian merupakan factor yang akan dicobakan pada pelaksanaan pembelajaran mikro (micro teaching) khususnya pada mahasiswa program studi biologi. Utuk mengontrol percobaan tersebut digunakan satu kelas mahasiswa yang tidak menggunakan video klip dengan rubric penilaian, sehingga dalam penelitian ini dibutuhkan dua kelas percobaan yaitu kelas-A menerapkan video klip dengan rubric penilaian dan kelas-B (control/tanpa video klip dengan rubric penilaian). Secara rinci perlakuan tersebut dapat dilihat pada gambar berikut ini.

Tempat penelitian dilaksanakan di program studi pendidikan biologi pada semester genap 2017.

Variabel penelitian terdiri dua yaitu variable bebas dengan symbol VX yaitu aplikasi video klip dengan rubric keterampilan proses dan variable terikat dengan symbol VY adalah ketercapaian keterapilan proses pada dua kelas yang berbeda.

Populasi dalam penelitian ini adalah seluruh mahasiswa yang ikut matakuliah micro teaching berjumlah 120 sedangkan sampelnya berjumlah 60 orang, terdiri atas 30 orang pada kelas-A dan 30 orang pada kelas-B.

Alat yang digunakan adalah kamera video dan rubric penilaian keterampilan proses yang telah dipersiapkan sebelumnya sedangkan bahan adalah materi pelajaran yang diajarkan.

Jenis data adalah data kuantitatif yaitu besaran sampel yang di ambil pada populasi penelitian dengan sumber dari mahasiswa yang ikut matakuliah micro teaching

Pengumpuan data dilakukan dengan mengamati video klip pembelajaran dari mahasiswa dan diberikan nilai dengan menggunakan rubric penilaian keterampilan proses. Setelah itu dihitung perolehan nilai dalam bentuk persen dan mantabulasi itemitem ketarampilan proses yang kurang untuk dijadikan bahan refleksi jika standar ketuntasan yang diperoleh dari total.

Instrumen penelitian adalah rubric penilaian keterampilan proses. Teknik analisa data yang digunakan dalam pengujian hipotesis adalah uji $t$ dengan bantuan program SPSS. 16.0. uji hipotesis merupkan hal yg paling penting ketika melakukan penelitian, hipotesis dibagi menjadi dua yaikni hipotesis Ho (tidak ada hubungan 
antara variable penelitian $\mathrm{x}$ dan $\mathrm{y}$ ) dan $\mathrm{Ha}(\mathrm{ada}$ hubungan antara variable penelitian $\mathrm{x}$ dan $\mathrm{y}$ ).

\section{HASIL DAN PEMBAHASAN}

Program studi Pendidikan Biologi merupakan program studi menghasilkan mahasiswa yang mampu dalam menguasai bidang keilmuannya, sala satunya adalah kemampuan dalam mengajar sebagai calon guru yang professional sehingga dalam pembelajaran di Program studi pendidikan Biologi selalu terkait dengan bagaimana menjadi seorang guru yang profesional, sala stu pemelajaran yang dilakukan dalm pencapaian tujaun tersebut adalah pembelajaran mikro (Micro-Teacing). Penggunaan pembelajaran mikro sebagai sala satu mata kuliah yang dianggap mampu meningkatkan keprofesionalan mahsiswa pendidikan Biologi sebagai calon guru pada keahlian mengajar mereka. Mengajar merupakan pekerjaan professional yang memerlukan keahlian yang ditempu melalui pendidikan dan pengalaman. Untuk dapat melaksanakan tugas dan tanggung jawab secara professional, guru harus memiliki kemampuan dan keterampilan mengajar secara teori maupun praktek, kemampuan mengajar merupakan kemampuan intelektual, keterampilan mengajar, bakat, dan seni.

Keterampilan mengajar dapat dilatih secara terus-menerus melalui pelatihan mengajar, kemampuan intelektual dapat dipelejari dari teori pendidikan dan teori belajar mengajar, sedangkan bakat dan seni mengajar dapat dikembangkan melalui berbagai pengalaman mengajar, pengalaman yang demikan sehingga mahasiswa pendidikan biologi dapat diberikan pengalam untuk meningkatkan kemampuan mereka dalam mengajar, dalam penelitian yang kami lakuakan adalah, pembelajarn mikro-teacing yang disertai penggunaan vidio klep dan penduan berupa rublik, dalam proses mengajar, ini memberikan asumsi bahwa semua pembelajaran dapat terekam dengan baik sesuai alur dalam proses pembelajaran yang dilakuakan, dari penelitian tersebut kami melakuakan pada dua kelas yang masing-masing berjumlah sebanyak 30 orang sebagai sampel, dari kedua kelas tersebut sala satu kelas tidak menggunakan rublik atau alur dalam pembelajar, sedanggakan yang satu menggunakan rublik hasil menunjukan bahwa ada perbedaan pencapaian pada dua kelas tersebut seperti yang terlihat pada tabel berikut

Tabel 1. Perolehan Nilai Mahasiswa Kelas A

\begin{tabular}{cccc}
\hline Nama Mahasiswa & Nilai & Nama Mahasiswa & Nilai \\
\hline Aditiya & 98 & Tirsa naftalia & 95 \\
Idawati & 100 & Yane sintia papia & 95 \\
Ilmawati & 98 & Moh. fadli ilahi & 98 \\
Mariska septirina & 98 & Novita & 100 \\
Nirmawati & 98 & Nur Ilma & 100 \\
Nurhaida dg mangawing & 98 & Almawati henggani & 100 \\
Riana dian pratiwi & 95 & Feni afianita & 95 \\
Uun nadianti & 98 & Rizal idris & 98 \\
Marwah & 98 & Sri safitri & 98 \\
Agnes & 98 & Hartin & 100 \\
Ika & 95 & Laura fouriana & 95 \\
Richard & 95 & Ni kadek puspayani & 98 \\
Jenny indriani & 95 & Sasmita & 95 \\
Norvita dewi losso & 98 & Widi triana & 95 \\
Nursaktiana & 95 & Abdul arif & 95 \\
\hline
\end{tabular}


Tabel 2. Perolehan Nilai Mahasiswa Kelas B

\begin{tabular}{cccc}
\hline Nama Mahasiswa & Nilai & Nama Mahasiswa & Nilai \\
\hline Demi rilandasari & 65 & Mardiah & 75 \\
Ririapriani & 83 & Alfianti & 75 \\
Mia meilinda & 85 & Rugayah & 68 \\
Sri wahyuni & 88 & Arif rahman hakim & 68 \\
Fadlun hajar & 80 & Deviyanti wulandari & 65 \\
Andi ariani & 73 & Zulfianti & 58 \\
Novita & 78 & Siti hartina & 65 \\
Widi triana putri & 70 & Siti maisarah & 70 \\
Ikhwan amirul & 68 & Dwi kurnia & 65 \\
Komang yunit sari & 78 & Manap trianto & 68 \\
Handoko & 85 & Citra firah laongko & 65 \\
Niluh devi sintia dewi & 78 & Nur amina & 73 \\
Roslianti sidik & 83 & Albaniah & 80 \\
Sarifah wadah & 78 & Atika bobide & 63 \\
Fatma & 70 & Ikomang adi putranata & 60 \\
\hline
\end{tabular}

Tabel 1 dan 2 meperlihatkan perolehan nilai yang berbeda pada mahasiswa biologi yang melakuakan proses mengajar dengan menggunakan pengamatan melalui vidio dengan rublik dan melalui vidio dengan tidak menggunakan rublik ini terlihat perbedaan yang sangat besar, sedangkan terlihat bahwa perbedaan nila yang diperoleh dalam proses penelitian pada dua kelas yang berbeda tersebut menunjukan pula sebuah ketercapaian yang keterampilan mengajar yang dilakukan oleh mahasiswa biologi akan terekam baik melalui vidio dengan rublik. Selanjutnya perbedaan prolehan nila tersebut dapat di uji dengan menggunakan uji t guna pengujian hipotesis.

Hipotesis yang diajukan dalam penelitian ini berbunyi terdapat pengaruh vidio dengan rublik terhadap peningkatan keterampilan mengajar mahasiswa biologi. Hasil pengujian hipotesis menggunakan uji t dengan bantuan SPSS disajiakan pada tabel berikut:

Tabel 3. Hasil Uji-t

\begin{tabular}{|c|c|c|c|c|c|c|}
\hline \multirow{2}{*}{ Kelas } & \multirow{2}{*}{ Rerata } & \multicolumn{2}{|c|}{ Hasil Uji } & \multirow{2}{*}{ t.tab } & \multirow{2}{*}{ A } & Ketrangan \\
\cline { 3 - 4 } & & t.hit & Sig & & \\
\hline A & 97.13 & & & & & Ho ditolak \\
B & 72.67 & 15.833 & 0.000 & 1.545 & 0.05 & \\
\hline
\end{tabular}

Output hasil uji hipotesis dengan uji t pada table diatas dapat diketahui t.hitung $=$ $15,833>$ t.tabel $(29: 0,05)=1,545$ dengan nilai signifikansi $0,000<\alpha(0,05)$. Hal tersebut menunjukan bahwa rata-rata perolehan nilai pada saat mangajar dengan menggunakan vidio dan rublik sebagai acuan dan menggunakan vidio tidak menggunakan rublik terdapat perbedaan. Dimana rerata perolehan hasil pengamatan pada kelas A sebagai kelas ekperimen yaitu 97,13 dan rerata hasil belajar kelas control yaitu 72,67. Maka dapat disimpulkan bahwa H0 ditolak dan H1 diterima. Hal ini berarti terdapat pengaruh vidio dengan rublik terhadap peningkatan keterampilan mengajar mahasiswa biologi.

Uji t dilakukan untuk mengetahui ada atau tidak adanya pengaruh vidio dengan rublik terhadap peningkatan keterampilan mengajar mahasiswa biologi. Hasil pengujian hipotesis dengan statistic uji t menggunakan 
program SPSS diperoleh t.hutung $=15,833>$ t.tabel $(29: 0,05)=1,545$ dengan nilai signifikansi $0,000<\alpha(0,05)$. Sehingga dapat disimpulkan bahwa $\mathrm{H} 0$ ditolak dan $\mathrm{H} 1$ diterima, yaitu terdapat pengaruh. Artinya hasil tersebut menunjukan pengaruh penggunaan vidio dengan rublik dibandingkan dengan vidio tidak dengan rublik.

\section{KESIMPULAN}

Dari hasil penelitian yang dilakukan maka dapat di tarik sebuah kesimpulan bahwa penggunaan vidio dalam pelaksanaan praktek mengajar atau mikroteacing akan lebih evektif dalam pengamatan aktivitas mahasiswa dalam latihan atau prakte mengajar (microteaching), Indikator yang belum sepenuhnya dilakukan atau dikuasai oleh peserta Microteacing adalah elaborasi pada saat melakukan pembeajaran dalam microteacing

\section{DAFTAR PUSTAKA}

Arifin, Z. (2009). Evaluasi Pembelajaran: Prinsip Teknik Prosedur. Bandung: PT Remaja Rosdakarya.

Arikunto. S. (2010). Prosedur Penilaian Suatu Pendekatan dan Praktek. Jakarta: Rineka Cipta

\section{Pendidikan.Jakarta: BumiAksara}

Arsyad, A. (2009). Media Pembelajaran. Jakarta: PT. Rajawali Grafindo

Arthana, K P. dkk. (2005). Evaluasi Media Instruksional. Surabaya: Universitas Negeri Surabaya
Badan Standar Nasional Pendidikan (BSNP). (2006). Panduan Penyusunan Kurikulum Tingkat Satuan Pendidikan Jenjang Pendidikan Dasar dan Menengah. Jakarta : BSNP.

Depdiknas. (2007). Rencana Strategi Departemen Pendidikan Nasional (Revisi 1 April 2007). Depdiknas. Jakarta.

Karsli, F. dan Sahin, C. (2009). Developing worksheet based on science process skills: Factors affecting solubility. Dalam Asia-Pacific Forum on Science Learning and Teaching, Volume 10, Issue 1, Article 15, p.1.

Mahadewi, Luh Putu Putrini., I Dewa Kade Tastra., \& I Komang Sudarma. (2012). Media Video Pembelajaran. Singaraja: Universitas Pendidikan Ganesha.

Sadiman, Arief S., Rahardjo., Anung Haryono., \& Rahardjito. (2006). Media Pendidikan: Pengertian, Pengembangan, dan Pemanfaatan. Jakarta: PT RajaGrafindo Persada.

Sanjaya, Wina. (2008). Strategi Pembelajaran Berorientasi Standar Proses Pendidikan. Kencana Prenada Media Group. Jakarta

Sukirman, D. (2012). Pembelajaran Micro Teaching. Direktorat Jenderal Pendidikan Islam Kementerian Agama. Jakarta. 